\title{
Article
}

\section{Tunable Human Myocardium Derived Decellularized Extracellular Matrix for 3D Bioprinting and Cardiac Tissue Engineering}

\author{
Gozde Basara $^{1}{ }^{\mathbb{D}}$, S. Gulberk Ozcebe ${ }^{2} \mathbb{D}$, Bradley W. Ellis ${ }^{2}$ and Pinar Zorlutuna ${ }^{1,2, *}$ \\ 1 Aerospace and Mechanical Engineering Department, University of Notre Dame, Notre Dame, IN 46556, USA; \\ gbasara@nd.edu \\ 2 Bioengineering Graduate Program, University of Notre Dame, Notre Dame, IN 46556, USA; \\ sozcebe@nd.edu (S.G.O.); bellis4@nd.edu (B.W.E.) \\ * Correspondence: Pinar.Zorlutuna.1@nd.edu; Tel.: +1-574-631-8543
}

check for updates

Citation: Basara, G.; Ozcebe, S.G.; Ellis, B.W.; Zorlutuna, P. Tunable Human Myocardium Derived Decellularized Extracellular Matrix for 3D Bioprinting and Cardiac Tissue Engineering. Gels 2021, 7, 70. https: //doi.org/10.3390/gels7020070

Academic Editor: David Díaz Díaz

Received: 30 March 2021

Accepted: 7 June 2021

Published: 11 June 2021

Publisher's Note: MDPI stays neutral with regard to jurisdictional claims in published maps and institutional affiliations.

Copyright: (c) 2021 by the authors. Licensee MDPI, Basel, Switzerland. This article is an open access article distributed under the terms and conditions of the Creative Commons Attribution (CC BY) license (https:// creativecommons.org/licenses/by/ $4.0 /)$.

\begin{abstract}
The generation of 3D tissue constructs with multiple cell types and matching mechanical properties remains a challenge in cardiac tissue engineering. Recently, 3D bioprinting has become a powerful tool to achieve these goals. Decellularized extracellular matrix (dECM) is a common scaffold material due to providing a native biochemical environment. Unfortunately, dECM's low mechanical stability prevents usage for bioprinting applications alone. In this study, we developed bioinks composed of decellularized human heart ECM (dhECM) with either gelatin methacryloyl (GelMA) or GelMA-methacrylated hyaluronic acid (MeHA) hydrogels dual crosslinked with UV light and microbial transglutaminase (mTGase). We characterized the bioinks' mechanical, rheological, swelling, printability, and biocompatibility properties. Composite GelMA-MeHA-dhECM (GME) hydrogels demonstrated improved mechanical properties by an order of magnitude compared to the GelMA-dhECM (GE) hydrogels. All hydrogels were extrudable and compatible with human induced pluripotent stem cell derived cardiomyocytes (iCMs) and human cardiac fibroblasts (hCFs). Tissue-like beating of the printed constructs with striated sarcomeric alpha-actinin and connexin 43 expression was observed. The order of magnitude difference between the elastic modulus of these hydrogel composites offers applications in in vitro modeling of the myocardial infarct boundary. Here, as a proof of concept, we created an infarct boundary region with control over the mechanical properties along with the cellular and macromolecular content through printing iCMs with GE bioink and hCFs with GME bioink.
\end{abstract}

Keywords: 3D bioprinting; decellularized extracellular matrix; cardiac tissue engineering; gelatin methacryolyl; methacrylated hyaluronic acid; human induced pluripotent stem cell-derived cardiomyocyte; human cardiac fibroblasts; dual crosslinking

\section{Introduction}

Myocardial infarction (MI) is one of the most common cardiovascular diseases and has remained the main cause of death worldwide for decades [1,2]. Although many studies are dedicated to understanding the MI mechanism and potential therapeutic options on animals, research concerning human myocardium remains very limited [3]. For this reason, it is crucial to fabricate human benchtop models recapitulating the mechanical properties of both healthy cardiac tissue and fibrotic scar tissue, which is formed as a result of the collagen deposition and fibroblast activation triggered in response to the MI and has an increased stiffness [4].

$3 \mathrm{D}$ bioprinting is one of the most powerful tools used to fabricate mimetic cardiac tissues, capturing the complexity of the native cellular composition and matrix structure [5-8]. These printed constructs have been used in different applications including but not limited to drug screening and regenerative medicine $[5,7,8]$. Extrusion-based bioprinting is one 
of the most commonly used 3D bioprinting methods [9-12], in which cell-laden bioinks are extruded on a platform following a pre-designed shape. For this process, the viscoelastic properties of the bioinks are explicitly important for printability while ensuring cell viability [4]. Natural hydrogels like collagen [13,14], gelatin [12,15,16], alginate [17,18], and hyaluronic acid (HA) $[19,20]$ have been widely used as bioinks for extrusion-based bioprinting. However, they fall short on fully capturing the biochemical cues of the native tissue microenvironment.

To obtain naturally derived biomaterials recapitulating the biochemical cues in the native tissue environment, decellularization techniques have been developed and decellularized ECM (dECM) has become a preferred biomaterial for cardiac tissue engineering applications such as cardiac repair and regeneration [21-25]. In addition to being able to mimic the complexity of the native tissue and recreate a microenvironment with improved cell-cell connections and 3D cellular organization, the age of AECM was shown to affect cell response, thus by using $\mathrm{dECM}$, the effect of age can also be introduced in the in vitro models [26]. Although dECM preserves the biochemical composition of the native tissue, it loses the mechanical and structural stability of tissue during the decellularization and digestion processes. Therefore, for printing purposes, $\mathrm{AECM}$ is usually crosslinked via mixing it with B2 vitamin [24], adjusting the $\mathrm{pH}$ [22], or combined with some other natural or synthetic biomaterials $[4,13,21,25,27-31]$. These biomaterials provide additional control over scaffold stiffness, which can be used to mimic the parameters of cardiac tissues of varying ages or pathologies.

Gelatin methacryolyl (GelMA) is a very commonly used natural hydrogel for both cardiac tissue engineering and 3D printing applications [12,32,33]. For some applications, the mechanical properties and printability of GelMA can be a limitation. Therefore, GelMA blends have been created by introducing various materials into GelMA hydrogels. To tune the mechanical properties of GelMA, biopolymers such as dextran [34], silk fibroin [35], HA [36], and gellan gum [37] have been incorporated into GelMA. Additionally, the printability of GelMA was enhanced by creating composite hydrogels with methylcellulose [38], gellan gum [39], HA (to increase viscosity) [40], collagen (to improve shape fidelity) [41], and laponite, a type of nanosilicate to rheologically modify GelMA [42].

Methacrylated HA (MeHA) has been commonly used in bone tissue engineering applications due to its increased rigidity and resistance to degradation [43]. Previous studies have shown that GelMA-MeHA hybrid hydrogels display highly tunable physical properties and can be used for different applications [19,36]. Unfortunately, the literature lacks a complete mechanical characterization, compatibility, and printability investigation of GelMA and GelMA-MeHA hydrogels mixed with dECM for cardiac tissue engineering applications.

In our study, we mixed GelMA and GelMA-MeHA hydrogels with decellularized human cardiac ECM (dhECM) to create cardiac tissue-like constructs. We measured the elastic modulus of GelMA (G), GelMA-dhECM (GE), GelMA-MeHA (GM), and GelMAMeHA-dhECM (GME) hydrogels that were dual crosslinked using UV and microbial transglutaminase (mTGase) and observed an order of magnitude difference between the GE and GME hydrogels. The fabricated gels were then characterized in terms of swelling, degradation, rheology, printability, and compatibility of human induced pluripotent stem cell-derived cardiomyocytes (iCMs) and human cardiac fibroblasts (hCFs). We then characterized iCMs printed with $\mathrm{G}$ and $\mathrm{GE}$ in terms of beating properties and protein expression. Finally, knowing that there was an approximately ten-fold difference between the stiffness of healthy cardiac tissue $(8-12 \mathrm{kPa})$ and scar tissue (>150 kPa) formed after myocardial infarction (MI), an infarct region model was printed using a dual printhead by mixing iCMs with GE to model the healthy tissue and hCFs with GME to represent the scar tissue. To our knowledge, this is the first study to characterize GE and GME composite hydrogels and demonstrate their potential through the printing of an infarct boundary zone using $\mathrm{iCMs}$ and hCFs to create a human myocardial infarct boundary model. 


\section{Results and Discussion}

\subsection{Decellularization and Solubilization of Human Cardiac Tissue}

Hearts that were deemed unsuitable for transplant were removed by the acting transplant surgeon and stored in a cardioplegic solution and transported to the University of Notre Dame with a transport/storage time of 1-8 h. Donor hearts were then cut into regionspecific pieces. Left ventricles were sectioned and decellularized as shown in Figure 1A,B. Cell-free ECM is composed of the structural proteins as well as the secreted products of the resident cells [44]. Preservation of the ECM biochemical composition is crucial since ECM provides bioactive cues that affect cell response to its environment such as proliferation, migration, and differentiation $[21,26,45]$. Therefore, to ensure human cardiac tissue decellularization with the preservation of ECM bioactivity, we optimized previous decellularization methods [46,47] and used a combination of ionic and non-ionic detergent washes. Due to the fatty nature of the human heart, we also added an alcohol-based delipidation step following decellularization. By conducting hematoxylin and eosin (H\&E) staining, the absence of DNA was confirmed and Masson's trichrome was used to show preservation of ECM proteins (Figure 1C). In addition, the double-stranded DNA content was measured and verified to be less than $50 \mathrm{ng} / \mu \mathrm{l}$ before using dhECM as the bioink (Figure 1D). dhECM was then solubilized and mixed with the other hydrogels prior to printing.

A

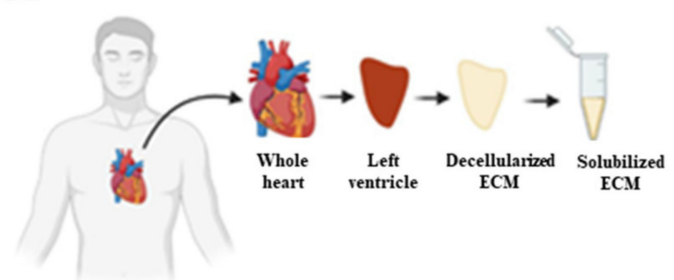

C

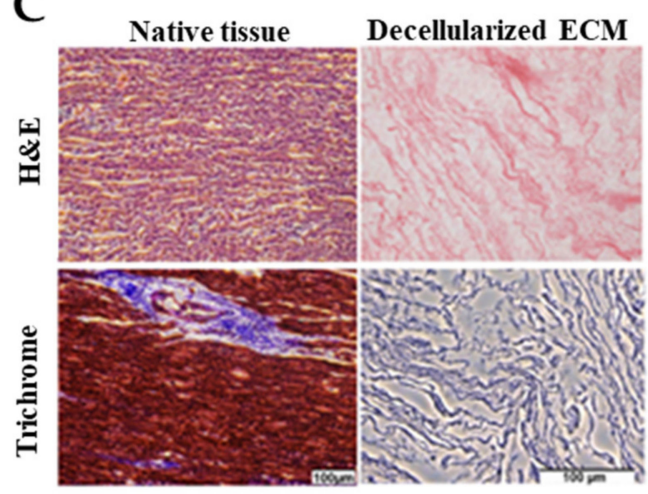

B

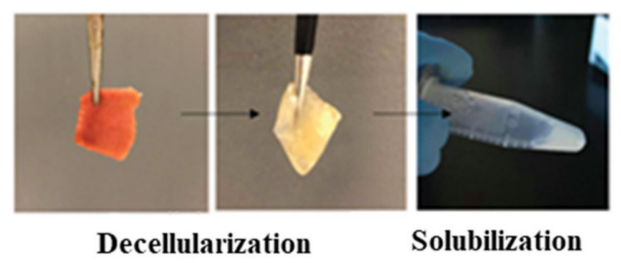

D

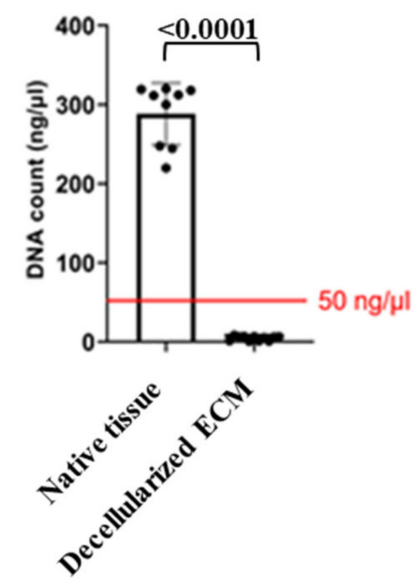

Figure 1. Decellularization of the native tissues and their biochemical analysis. (A) Schematic and (B) representative images demonstrating the workflow of the decellularization and solubilization process, $(\mathrm{C})$ hematoxylin and eosin (H\&E) and Masson's Trichrome staining of native tissue and dhECM, and (D) quantitative measurements of total DNA content of native, decellularized cardiac tissue.

\subsection{Physical Characterization}

GelMA and MeHA hydrogels were synthesized by incorporating methacrylate groups to gelatin and HA, and the degree of methacrylation was quantified as $66.9 \%$ for GelMA and $10.0 \%$ for MeHA using ${ }^{1} \mathrm{H}$ NMR (Figure S1). dhECM mixed with either GelMA alone or GelMA-MeHA yielded different material properties. Mixing dhECM with both polymers increased the Young's modulus significantly. Moreover, by including a second crosslinking step with mTGase, the mechanical properties of the hydrogel blends were further improved. 
Using a nanoindenter a uniaxial compression test was performed, and Young's modulus of each hydrogel was determined (Figure 2A). The Young's modulus of the hydrogels without and with mTGase treatment was measured to be $2.4 \pm 0.4 \mathrm{kPa}$ and $3.5 \pm 0.5 \mathrm{kPa}$ for G, $0.6 \pm 0.1 \mathrm{kPa}$ and $2.8 \pm 0.7 \mathrm{kPa}$ for GE, $14.4 \pm 1.8 \mathrm{kPa}$ and $24.5 \pm 2.9 \mathrm{kPa}$ for GM, and $9.9 \pm 2.6 \mathrm{kPa}$ and $18.4 \pm 2.8 \mathrm{kPa}$ for GME, respectively ( $n \geq 3$ for all). The improved elastic modulus of the GM hydrogels most likely resulted from the increased polymer concentration and crosslinking sites [48]. These results also demonstrate that mTGase treatment improved the Young's modulus of the hydrogels, which is in agreement with the results shown in previous studies [33,49]. Moreover, constructing composite hydrogels by mixing dhECM with G and GM allowed us to tune the Young's modulus values in a wide range from $0.6 \mathrm{kPa}$ to $18.4 \mathrm{kPa}$. This range can be further widened by changing the concentrations of GelMA and MeHA individually and mixing them in different ratios, as shown previously [36].

For the rest of this study, the two-step crosslinking method was used to create tissue constructs at a stiffness comparative to native human heart tissue $(\sim 10 \mathrm{kPa})$ [50]. For the swelling analysis, the volume of the hydrogels was measured after $24 \mathrm{~h}$ of incubation at $37^{\circ} \mathrm{C}$, allowing the gels to reach equilibrium swelling. G was observed to be swollen the least with $6 \% \pm 4 \%$, and the others showed comparable swelling properties with $12 \% \pm 3 \%$ for GE, $14 \% \pm 5 \%$ for GM, and $15 \% \pm 5 \%$ for GME, respectively, as shown in Figure 2B. Previous studies have shown that introducing MeHA to low concentration GelMA hydrogels $(<10 \%)$ lowers the swelling ratio, whereas remains ineffective in gels with greater than $10 \%$ GelMA when only UV crosslinking was applied [36]. In this study, dual crosslinking allowed for further crosslinking of GelMA without altering the MeHA polymers. It is well-known that higher crosslinking density results in smaller pore sizes [48]. We hypothesize that this is the reason for the reduced swelling ratio in the GelMA gels and plan to expand upon these findings in future studies.

The controlled degradation of the composite hydrogels was performed using collagenase for the $\mathrm{G}$ and GE hydrogels and using the collagenase-hyaluronidase mixture for the GM and GME hydrogels. The degradation rate of G and GE hydrogels were very similar, and the hydrogels degraded completely in $5 \mathrm{~h}$, whereas the required time for complete degradation of GM and GME hydrogels was observed to be $24 \mathrm{~h}$ and $18 \mathrm{~h}$, respectively (Figure 2C).

SEM images revealed different porous structures for each hydrogel (Figure 2D). Even though the lyophilization procedure can change the material porosity, a comparison can be made between different hydrogels lyophilized using the same drying process, indicating a fundamental difference in the hydrogel structures. G and GM hydrogels had noticeably smaller pores compared to the dhECM containing GE and GME hydrogels, which appeared to be distinct and separated by thin walls.

A

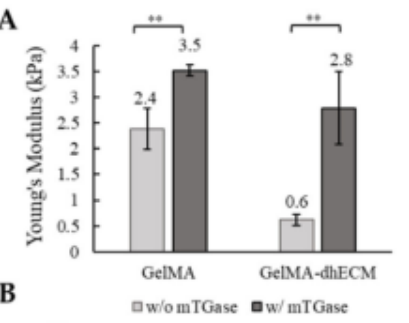

B

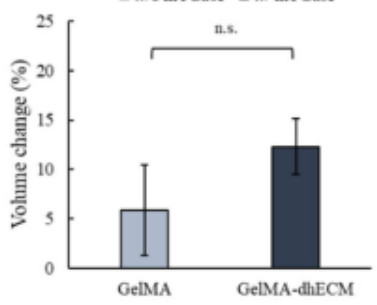

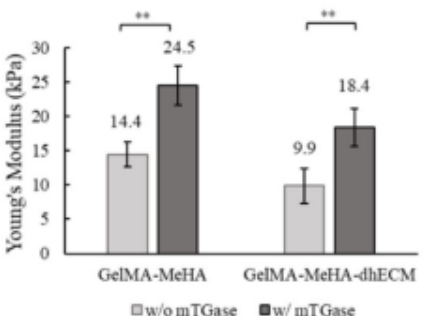

n.s.

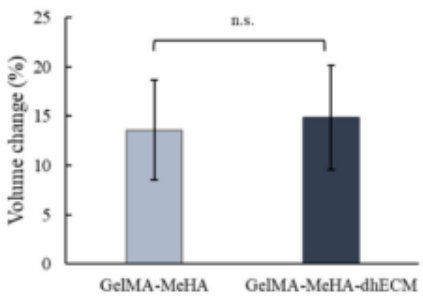

Figure 2. Cont. 
C
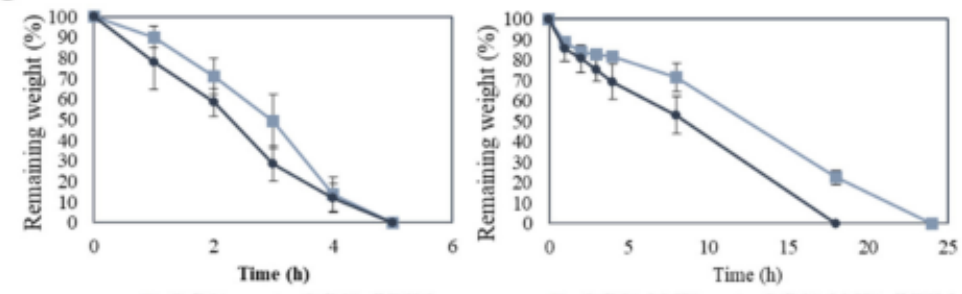

D
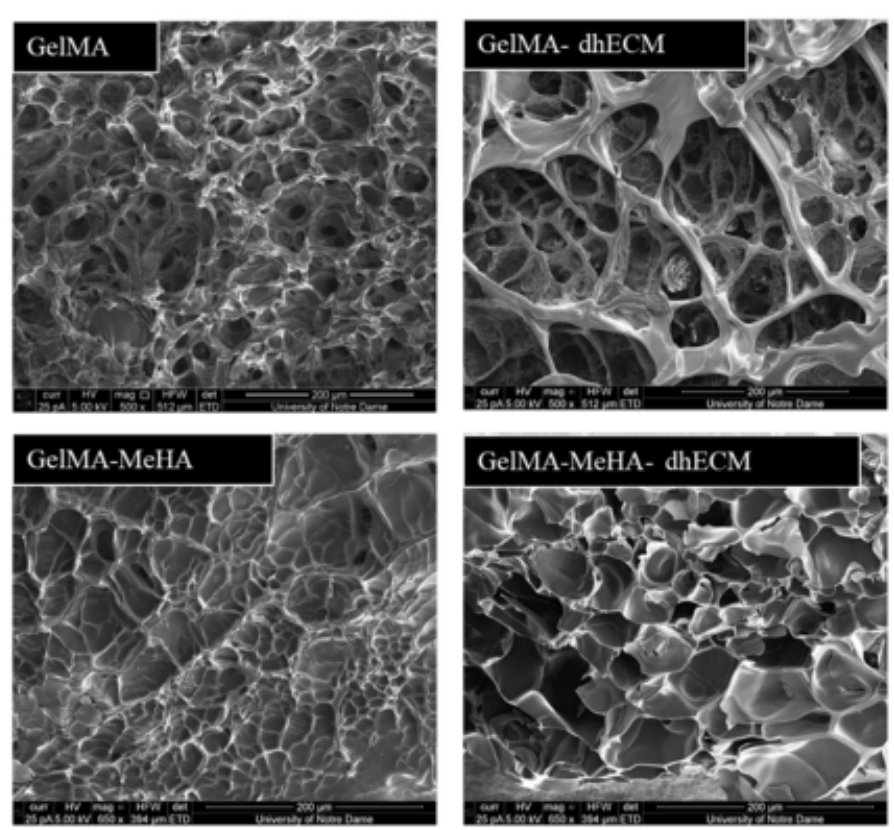

Figure 2. Mechanical and swelling characteristics of the hydrogels. (A) Young's modulus values of GelMA and GelMA-dhECM hydrogels without and with microbial Transglutaminase (mTGase) treatment (left), of GelMA-MeHA and GelMA-MeHA-dhECM hydrogels without and with mTGase treatment (right), (B) Swelling properties of GelMA and GelMA-dhECM hydrogels with mTGase treatment (left), of GelMA-MeHA and GelMA-MeHA-dhECM hydrogels with mTGase treatment (right), (C) Controlled enzymatic degradation of GelMA and GelMA-dhECM hydrogels with mTGase treatment (left), of GelMA-MeHA and GelMA-MeHA-dhECM hydrogels with mTGase treatment (right), (D) Scanning electron microscopic images of lyophilized GelMA and GelMA-dhECM hydrogels with mTGase treatment (top), of GelMA-MeHA and GelMA-MeHA-dhECM hydrogels with mTGase treatment (bottom). (** $p<0.01$, n.s.: not significant) (Student's $t$-test) $(n \geq 3)$.

\subsection{Rheological Characterization}

In order to better ascertain the potential printability of the hydrogel blends, we utilized rheological experiments to measure various viscoelastic properties. First, the storage and loss modulus of each hydrogel blend was determined at a fixed frequency of $1 \mathrm{~Hz}$ and strain of 3\%. GM hydrogel had the greatest storage and loss modulus with $8086.7 \pm 83.8 \mathrm{~Pa}$ and $3203.1 \pm 73.8 \mathrm{~Pa}$, respectively. The storage and loss modulus of G and GE were nearly identical with storage modulus values of $4895.7 \pm 170.3 \mathrm{~Pa}, 4714 \pm 16.8 \mathrm{~Pa}$, and with loss modulus values of $2309 \pm 34.2 \mathrm{~Pa}$ and $2304 \pm 17.3 \mathrm{~Pa}$, respectively. Finally, GME had a storage modulus of $537.8 \pm 14.0 \mathrm{~Pa}$ and a loss modulus of $295.6 \pm 5.9 \mathrm{~Pa}$ (Figure 3A). To observe the relationship between storage and loss modulus with respect to frequency, the hydrogels were kept at a strain of $2 \%$ over a frequency range from 0.1 to $10 \mathrm{~Hz}$. A slight decrease in the storage modulus and a slight increase in the loss modulus were observed in each group (Figure 3B). The storage and loss modulus of G and GM gels remained the same, indicating preserved solid-like structures. However, when dhECM was added to the GM, the decrease in the storage modulus and the increase in the loss modulus were more distinct, suggesting that the increasing frequency weakened the link between the polymer chains. 
Finally, a flow ramp experiment was conducted for a shear range between 0.1 to $901 / \mathrm{s}$ and the shear rate-viscosity graphs were plotted. G and GE had similar viscosities whereas GM was significantly more viscous compared to GME (Figure 3C). As expected for shearthinning hydrogels, viscosity dropped with increasing shear rate. Using the power-law model shown in Equation (1), the shear-thinning behavior of the hydrogels was quantified, where $\tau$ is shear stress, $\dot{\gamma}$ is the shear rate, $n$ is the power-law index, and $\mathrm{K}$ is the consistency index, and the results were summarized in Table 1.

$$
\tau=K \dot{\gamma}^{n}
$$
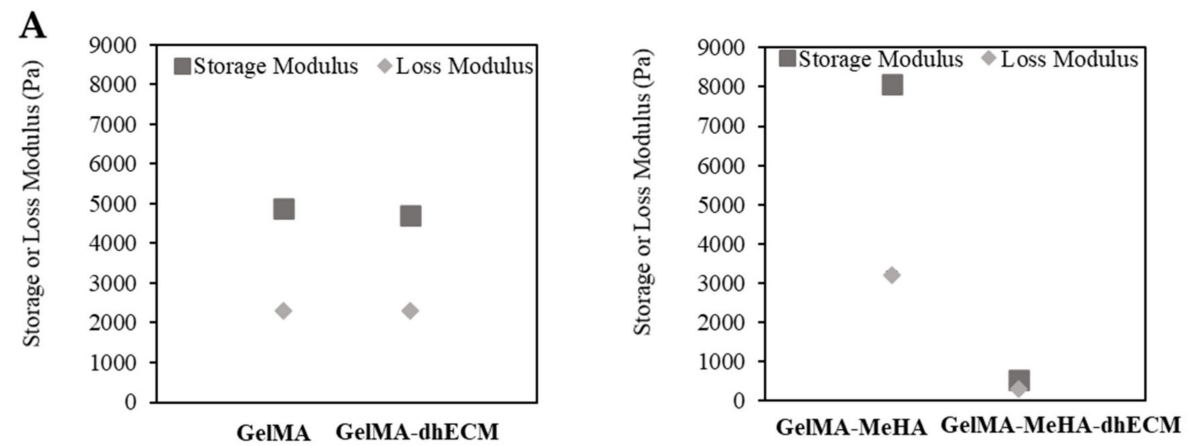

B
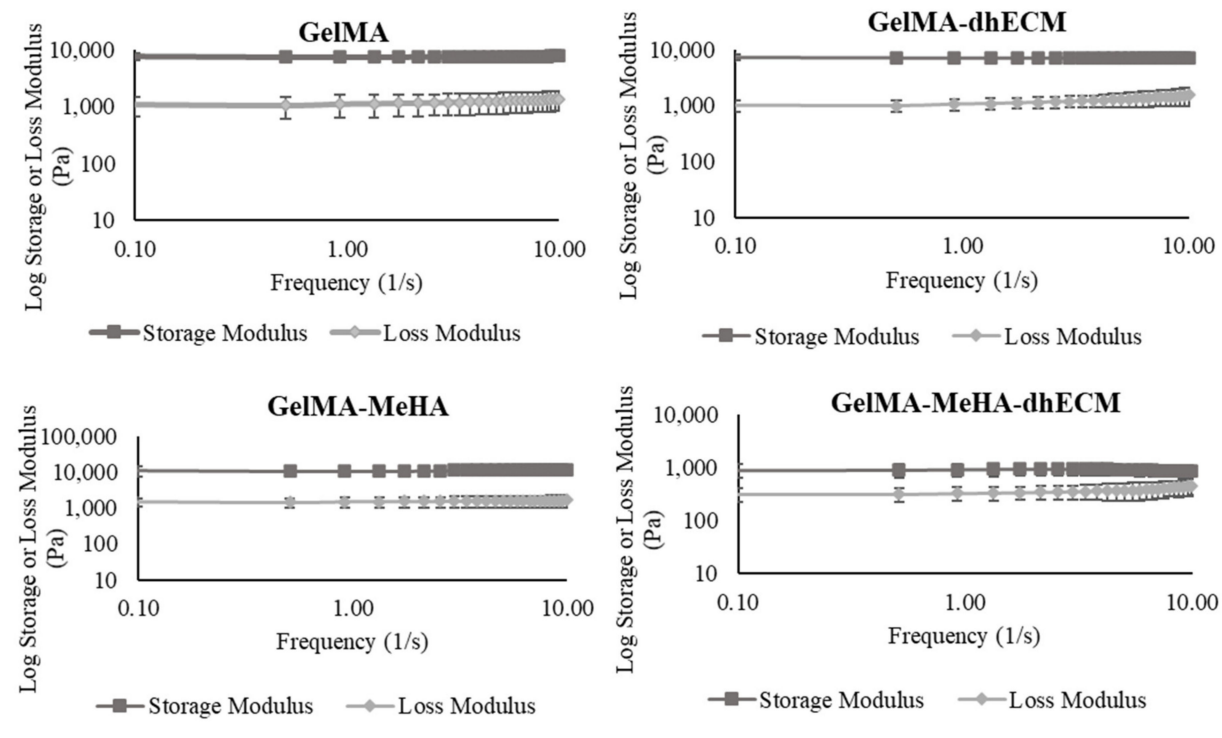

C
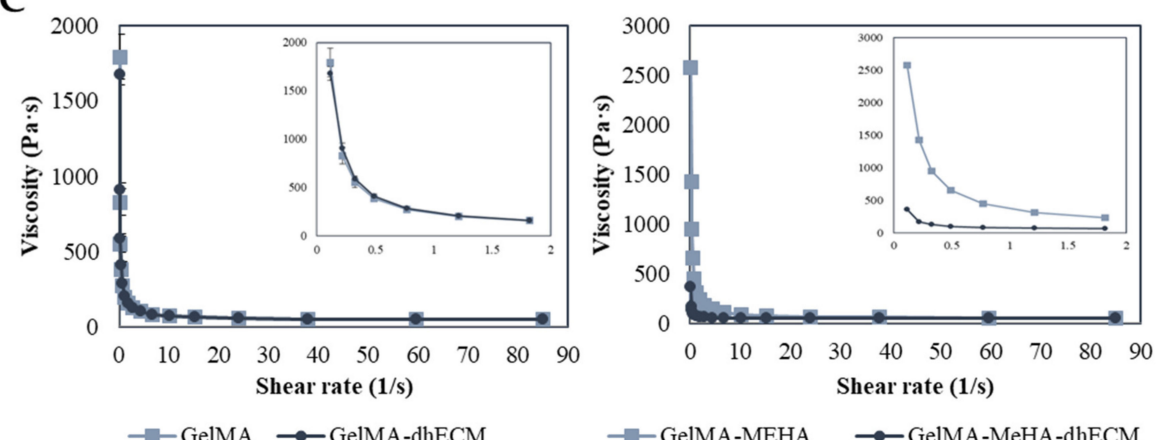

Figure 3. Viscoelastic properties of GelMA, GelMA-dhECM, GelMA-MeHA, GelMA-MeHAdhECM hydrogels. (A) Storage and lost modulus values at a constant frequency of $1 \mathrm{~Hz}$ and a strain of $3 \%$, (B) Change of storage and loss modulus with respect to frequency at a strain of $2 \%$, (C) Plots of viscosity vs. shear rate, inset panels showing the change of viscosity with a smaller shear rate change $(n \geq 3)$. 
Table 1. The calculated values of $n$ and $K$ from the power model.

\begin{tabular}{ccc}
\hline Sample & $\boldsymbol{n}$ & $\boldsymbol{K}$ \\
\hline GelMA & 0.48 & 287.92 \\
GelMA-dhECM & 0.48 & 295.79 \\
GelMA-MeHA & 0.42 & 439.26 \\
GelMA-MeHA-dhECM & 0.76 & 100.1 \\
\hline
\end{tabular}

The power-law index is one for Newtonian fluids, whereas for shear-thinning solutions, it is lower than one. For all hydrogels, the power-law index was lower than one, signifying the shear-thinning behavior of the hydrogels tested in this study [51]. Moreover, the $K$ value, which is a sign of viscosity at low shear rate, was the largest for GM and the smallest for GME hydrogels, indicating the poorer printability of the GME bioink [38].

Considering the elastic modulus results, it was expected that the GM and GME hydrogels would have superior viscoelastic properties compared to the G and GE hydrogels. However, the rheology experiments revealed that GME hydrogels had the smallest storage modulus and viscosity. This could be explained by the fact that the Young's modulus of the polymer blends was less sensitive to the interaction and morphological changes than the yielding properties [52]. The reason for observing such a drastic difference for the GME hydrogels and not observing it for the GE hydrogels can be explained by the microscopic mixing of these hydrogel blends. The GME hydrogel blend can be classified as a compatible hydrogel blend, which has macroscopically uniform physical properties, but microscopically heterogonous properties, resulting in a lower yielding point under shear stress [53]. Moreover, SEM images revealed a different structure with relatively larger pores for the GME hydrogels (Figure 2D).

\subsection{D Printing}

To investigate the printability of the different hydrogels, 2-layered grid-shaped constructs $(6 \mathrm{~mm} \times 6 \mathrm{~mm})$ were printed with a $2 \mathrm{~mm}$ distance between neighboring lines. All hydrogel blends were printable, and the printed samples were dual crosslinked (Figure 4). The best printability was achieved with $G$, which best preserved the distance between neighboring lines that was measured as $1.6 \pm 0.1 \mathrm{~mm}$ (Figure $4 \mathrm{~A})$. Using GE and GM, the grid-shaped construct was also successfully printed (Figure 4B,C) and the distance between neighboring lines was measured as $1.6 \pm 0.2 \mathrm{~mm}$ and $1.5 \pm 0.1 \mathrm{~mm}$, respectively. It was observed that the GME bioink required a longer time in the ice bath ( 1.5-2 min) to reach the same consistency as the other bioinks ( 1-1.5 $\mathrm{min})$ prior to printing and its stability during printing was lower compared to the other blends, resulting in the greatest difference from the pre-design shape with the distance measured between neighboring lines as $1.3 \pm 0.2 \mathrm{~mm}$, which is in line with the rheology results (Figure 4D). A trend where the middle bottom square is greater than the middle top square can be seen for all materials. This might be due to the slight movement of the printing platform due to the vibration of the printhead. The effect of this vibration was minimized by placing parafilm both on the stage and inside the dish under the glass (Figure S2). Previous studies reported the printability of decellularized cardiac dECM alone [22], or dECM composites with PEGDA [4], HA, gelatin, and various crosslinkers [13], only MeHA [43], and only GelMA [54]. By mixing GelMA with dhECM and MeHA, our group was able to develop a novel, composite hydrogel that resulted in better printability compared to the printability of dECM [22] and MeHA [43] alone. Moreover, the pre-designed shape can be printed more accurately if a higher gauge nozzle is used [4]. Additionally, printing speed and pressure can be adjusted to improve printability; however, these parameters affect cell viability [55]. In our study, we investigated the cell viability when printed using a 22G nozzle with a translational speed of $75 \mathrm{~mm} / \mathrm{min}$ and a printing pressure of 20-30 $\mathrm{kPa}$. The individual effect of these parameters on cell viability can be investigated further in future studies. 


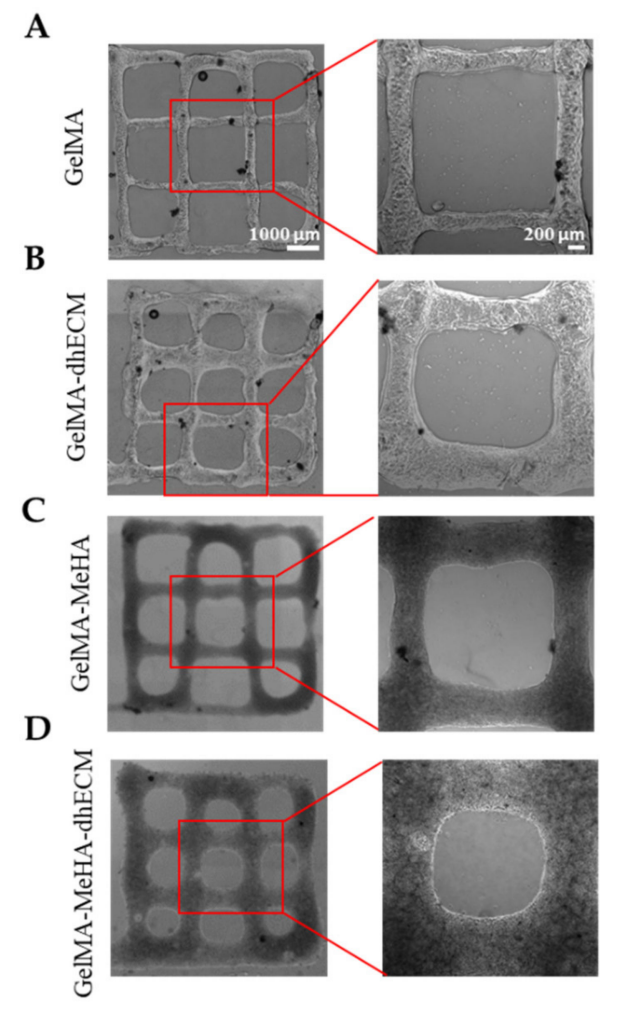

Figure 4. Brightfield images of 3D printed 2 layered-grid constructs using (A) GelMA, (B) GelMAdhECM, (C) GelMA-MeHA, (D) GelMA-MeHA-dhECM hydrogels $(n \geq 3)$.

\subsection{Cell Viability}

To evaluate the effect of the bioink composition on cell viability, iCM and hCFs were printed with $G$ and GM with or without dhECM supplementation. To recapitulate the healthy cardiac tissue, iCMs were printed with low stiffness $\mathrm{G}$ or GE bioinks ( 3.5 or $2.8 \mathrm{kPa}$ ) whereas hCFs were printed with high stiffness GM or GME bioinks ( 24.5 or $18.4 \mathrm{kPa}$ ) to represent the scar tissue. The day after printing, more than $65 \%$ of the cells were viable for each hydrogel (Figure 5). The percentage of live cells was calculated as $67 \% \pm 6 \%$ and $74 \% \pm 10 \%$ for iCMs printed in G only or GE bioinks, respectively (Figure $5 \mathrm{~A}, \mathrm{~B}, \mathrm{E}$ ). The viability of hCFs was $79 \% \pm 3 \%$ in GM and $84 \% \pm 3 \%$ when the cells were mixed with the GME bioink prior to printing (Figure 5C,D,F). Combining dhECM with G slightly improved iCM viability and a similar effect was observed for hCFs when dhECM was combined with the GM hydrogel.

The iCM viability reported in this study was slightly lower compared to previous studies in which the cells were printed using an extrusion-based printer with different bioinks, which may result from factors such as UV light treatment, mixing the cells with a photoinitiator (PI), and encapsulated cell density. As Koti et al. reported in their study, UV and PI are factors that negatively affect the cell viability along with the increasing gel concentration [12]. However, to meet the native tissue-like mechanical properties using $G$ and GM hydrogels, the addition of UV-sensitive PI and UV treatment are necessary while the hydrogels obtained using visible light crosslinking were measured to have a Young's modulus of less than $1 \mathrm{kPa}$ (Figure S3). Lee et al. printed highly concentrated iCMs and collagen in different printheads using collagen as a supporting material in a gel bath and reported the viability only immediately after printing as over $95 \%$ [14]. The difference observed in viability might have resulted from printing in a gel bath, not mixing the cells with any bioink or PI, high printing cell concentration, and assessing the viability immediately after printing. In another study, Kumar et al. used a fibrinogen-gelatin-based hydrogel with a visible-light-induced PI to print iCMs and reported cell viability over $90 \%$ [16]. The difference in viability could result from avoiding employing the UV-induced 
PI and polymerization with UV-light in their process. Despite the $\sim 70 \%$ viability quantified in this study, the healthy tissue-like beating of the cells was achieved (Video S1 (iCMs printed with G) and Video S2 (iCMs printed with GE)). Better viability and beating of the cells were observed when they were in close proximity with high cell-to-cell interaction, and when they were separately encapsulated, the chance of survival decreased, in agreement with our previous study [56]. The viability of the encapsulated iCMs might be improved by optimizing the cell density; however, this will disturb the homogeneity of the cell-gel mixture, affecting the printing ability and quality negatively. One other solution to improve viability might be introducing a perfusion system, allowing the media to reach through the thick tissue [14]. These and other methods could be explored to increase viability in future studies.

A
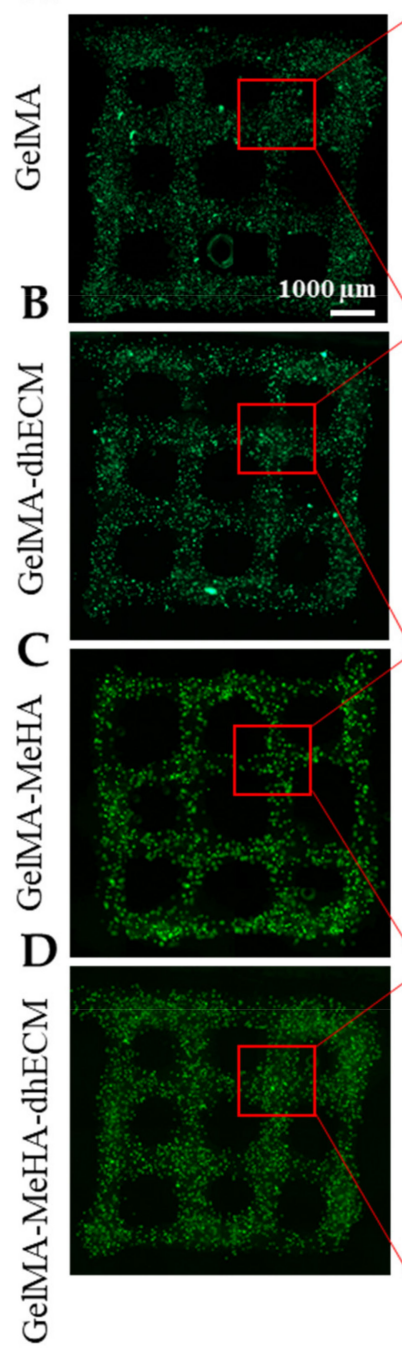

E
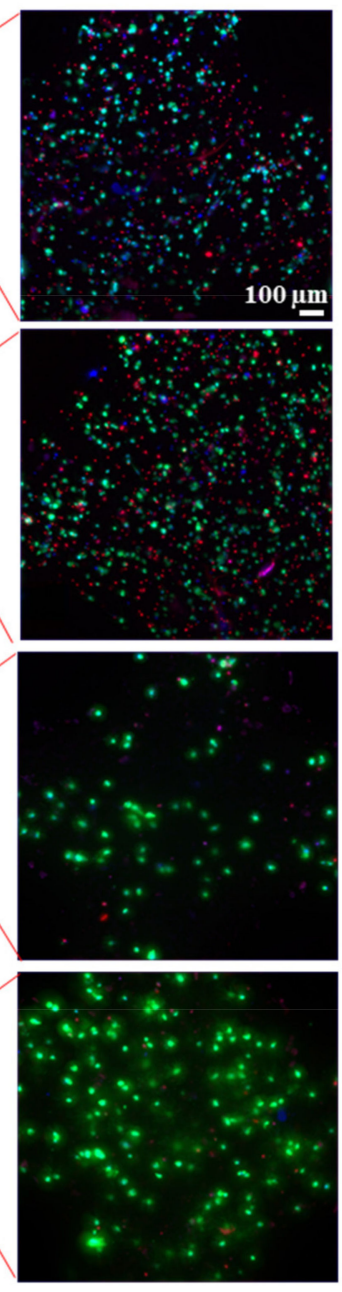
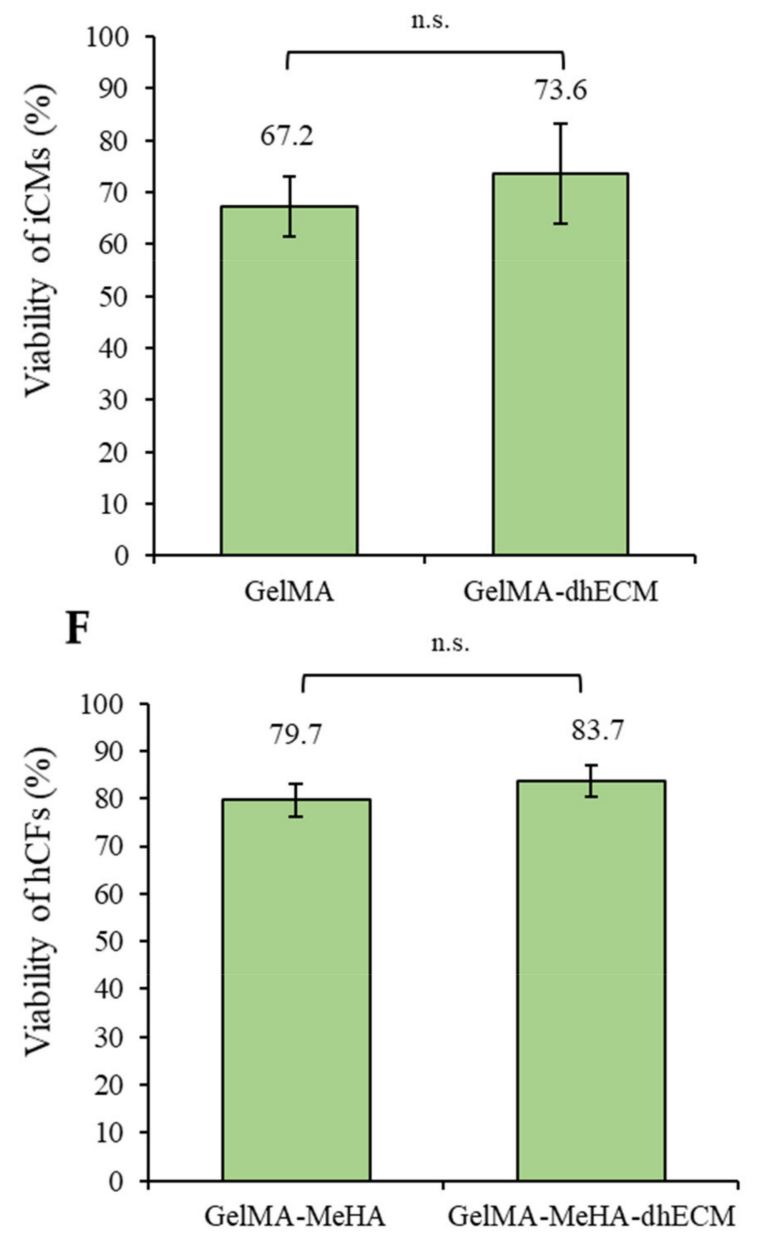

Figure 5. Cell viability analysis of the printed cell-laden hydrogels prepared using (A) GelMA, (B) GelMA-dhECM, (C) GelMA-MeHA, (D) GelMA-MeHA-dhECM, (E) live cell percentage comparison for GelMA and GelMA-dhECM, (F) live cell percentage comparison GelMA-MeHA and GelMA-MeHA-dhECM (n.s.: not significant) (Student's $t$-test) $(n \geq 3)$.

\subsection{Beating and Phenotypical Characterization of Printed Constructs}

Spontaneous beating was observed as soon as $24 \mathrm{~h}$ after printing. To investigate the beating characteristics of iCMs, brightfield videos were taken nine days after printing (Video S3 (iCMs printed with G) and Video S4 (iCMs printed with GE)). Beating velocity and frequency of the printed tissue constructs were quantified by video analysis of 
lateral displacement of spontaneous beating iCMs and heat maps were generated using a custom-made MATLAB code (Figure 6A,B). Beating velocity was measured to be $7.7 \mu \mathrm{m} / \mathrm{s} \pm 3 \mu \mathrm{m} / \mathrm{s}$ for $\mathrm{G}$ and $8.0 \mu \mathrm{m} / \mathrm{s} \pm 2 \mu \mathrm{m} / \mathrm{s}$ for GE (Figure $6 \mathrm{C}$ ) and beating frequency was calculated as $0.54 \mathrm{~Hz} \pm 0.30 \mathrm{~Hz}$ for $\mathrm{G}$ and $0.65 \mathrm{~Hz} \pm 0.26 \mathrm{~Hz}$ for GE (Figure 6D). As the results indicate, dhECM slightly improved beating kinetics and yielded faster iCM beating at higher frequencies. In previous studies, the beating velocities of the printed cardiac constructs were not reported. However, our results were in perfect alignment when iCMs were directly encapsulated in collagen hydrogel and the beating velocity was reported as $8 \mu \mathrm{m} / \mathrm{s}$ and frequency as $0.67 \mathrm{~Hz}$ [57].

A

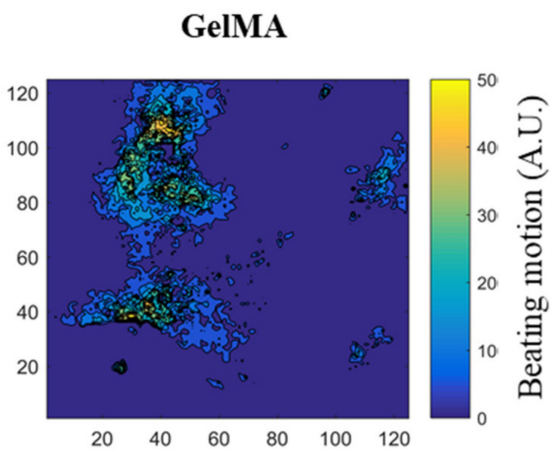

C

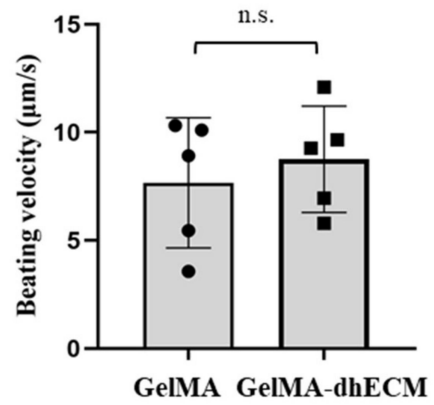

E

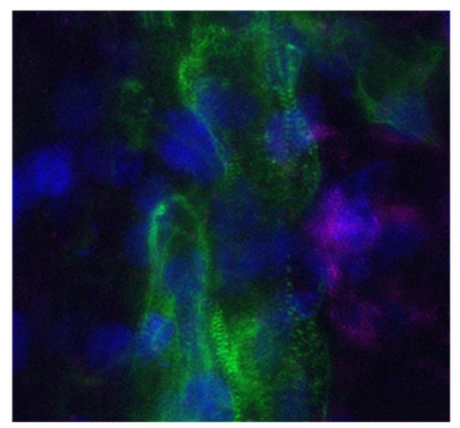

B

\section{GelMA-dhECM}

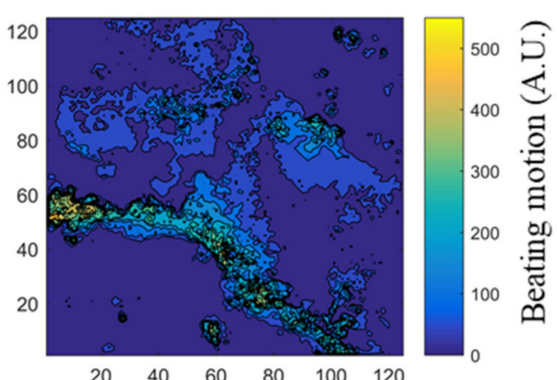

D

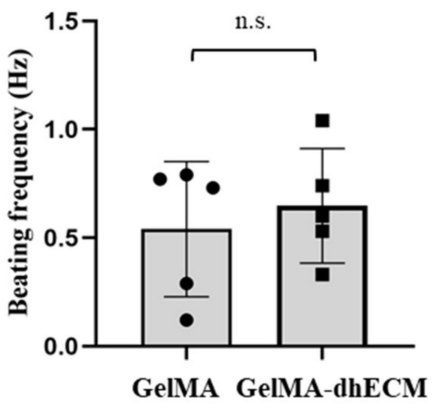

$\mathbf{F}$

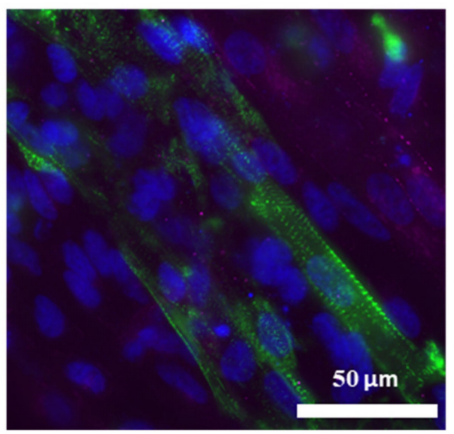

Figure 6. Beating and phenotypical characterization of iCMs. The heat maps showing the beating velocity magnitude (A.U.) and distribution of $\mathrm{iCM}$ (A) when they were printed in GelMA hydrogel, (B) when they were printed in the GelMA-dhECM hydrogel, (C) average beating velocity of iCMs, (D) average beating frequency of iCMs. Immunostaining of iCMs for CX43 (magenta) and sarcomeric alpha-actinin (green), (E) when they were printed in GelMA hydrogel, and (F) when they were printed in the GelMA-dhECM hydrogel. Cell nuclei are stained with DAPI (blue) (n.s.: not significant) (Student's $t$-test) $(n \geq 3)$.

On day 21 after printing, connexin 43 (CX43), a canonical cardiac intercellular junction protein, and sarcomeric alpha-actinin, a cytoskeletal actin-binding protein, expressions were investigated by immunostaining. For both G and GE hydrogels, iCMs showed CX43 
expression and striated sarcomeric alpha-actinin structure (Figure 6E,F). However, in the presence of dhECM, cells were more elongated and had organized striations like native CMs (Figure 6F). Similar organized striation of sarcomeric-alpha-actinin was observed in previous studies when the iCMs were patterned like native myocardium, which is important for developing higher contractile force as well as an indication of more mature cells $[58,59]$.

\subsection{D Printing the Infarct Boundary Region}

As shown in the previous section, the Young's modulus of GM and GME hydrogels were approximately an order of magnitude different from each other. This tunability in stiffness allows these materials to be used in a variety of applications. It is known that post-MI ECM remodeling yields scar tissue in vivo [60]. The scar tissue is significantly stiffer compared to healthy cardiac tissue and consists mostly of CFs and myofibroblasts [61]. As a proof of concept, an infarct boundary region was printed using GME mixed with hCFs to model the infarct region surrounded by the healthy tissue, which is modeled using GE bioink mixed with iCMs as shown in Figure 7A. This model has been used to demonstrate the infarct boundary region in previous studies [3,62]. Prior to printing, iCMs were tagged with a green cell tracker and hCFs were tagged with a deep red cell tracker (Figure S4). Fluorescent images were taken immediately following printing, showing the printing success with dual printheads, different materials, and cell types (Figure 7B). Immunostaining was performed on the printed products to demonstrate that the CFs were expressing fibroblast protein Vimentin and iCMs were expressing cardiac protein sarcomeric alpha-actinin (Figure 7C). Like our study, Koti et al. also printed using dual printhead to print "spatially defined 3D constructs" using rat CMs and CFs. Our study advances the field by introducing printing by using hydrogels supplemented with dhECM and human-derived cardiac cells and achieving various mechanical properties to better mimic the infarct region. Although the model achieved the order of magnitude difference in stiffness of healthy tissue and scar tissue, it falls short of achieving the physiologically accurate stiffness of myocardial tissue, which remains a limitation and will be addressed in future studies.

A

B

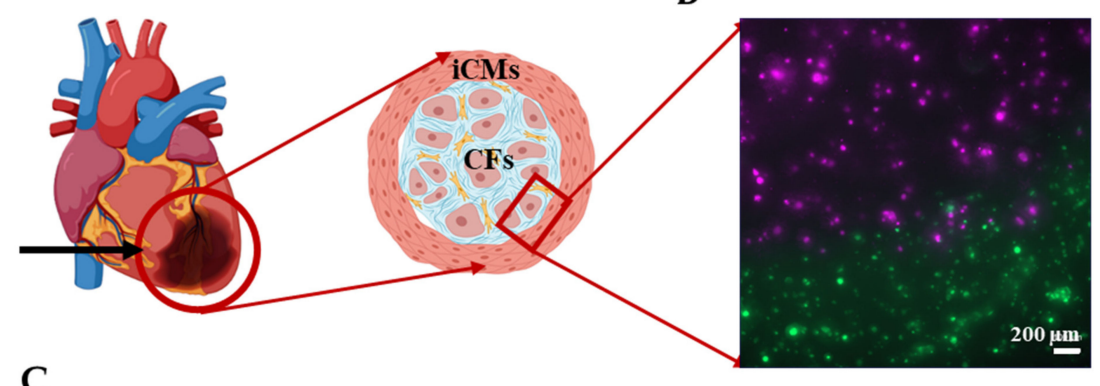

C

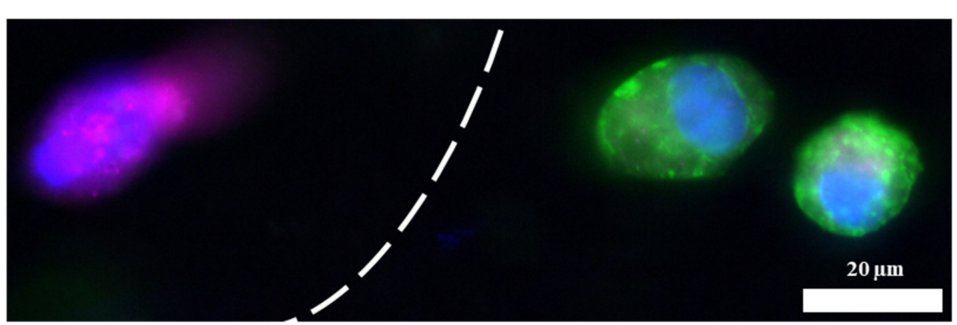

Figure 7. Printing the infarct region. (A) Schematic showing the infarct region model and corresponding cells. (B) Image showing the successful printing of the infarct region with iCMs (green) and hCFs (magenta). (C) Immunostaining of iCMs for sarcomeric alpha-actinin (green) and hCFs for Vimentin (magenta). Cell nuclei are stained with DAPI (blue). 


\section{Conclusions}

In this study, we showed the extrusion-based 3D printing of GelMA and GelMAMeHA with the addition of decellularized human cardiac tissue ECM. We fully characterized the mechanical properties of these bioinks and evaluated the cell compatibilities. We reported that the elastic modulus of GME hydrogel was an order of magnitude greater compared to the GE hydrogel. Leveraging this stiffness difference, we demonstrated as a proof of concept the potential use of GE and GME hydrogels with iCMs and hCFs, respectively, in mimicking post-MI cardiac tissue.

The fabricated 3D in vitro MI models can be used to study MI recovery and potential therapies including cardiac patches and cell injection with human cells. This model can also be used to better understand the relation between scar tissue and healthy tissue. Moreover, by mixing the iCMs and hCFs in different concentrations, better modeling of the infarct boundary region can be achieved. These newly developed bioinks and printing method can potentially provide researchers with tunable, printable hydrogels that can be used to mimic human physiological conditions in vitro, providing a crucial bridge between 2D in vitro and expensive long in vivo and clinical studies.

\section{Materials and Methods}

\subsection{Decellularization and Solubilization of Human Cardiac Tissue}

De-identified human hearts that were deemed unsuitable for transplantation and donated to research were acquired from the Indiana Donor Network. Hearts from donors were cut into region-specific pieces and stored at $-80{ }^{\circ} \mathrm{C}$ until further use. Left ventricles were sectioned and decellularized using $1 \%$ sodium dodecyl sulfate (SDS, VWR, Radnor, PA, USA) for $24 \mathrm{~h}$ or until the tissues turned transparent white. Then, the samples were transferred to 1\% Triton X-100 (Sigma-Aldrich, St. Louis, MO, USA) for $30 \mathrm{~min}$. After decellularization, samples were washed thoroughly with deionized (DI) water to remove any residual detergent. To delipidize, dhECMs were washed in isopropanol for $1 \mathrm{~h}$ and rehydrated via DI washes. All steps were conducted with constant agitation at room temperature (RT).

dhECMs were digested in a $1 \mathrm{mg} / \mathrm{mL}$ pepsin in $0.1 \mathrm{M} \mathrm{HCl}$ at RT with constant stirring until a homogeneous solution was obtained. The insoluble remnants were removed by centrifugation, the supernatant was neutralized using $1 \mathrm{M} \mathrm{NaOH}$ solution, and either used immediately or flash frozen and stored at $-80^{\circ} \mathrm{C}$ until use. Prior to the experiments, the total protein concentration was measured using the Rapid Gold BCA Assay (Thermo Scientific, Waltham, MA, USA) and dhECM solutions were diluted to $3 \mathrm{mg} / \mathrm{mL}$ with phosphate-buffered saline (PBS, Corning, Somerville, NY, USA).

\subsection{GelMA and MeHA Synthesis}

GelMA synthesis was performed by following a previously established protocol [63]. Briefly, $10 \mathrm{~g}$ of gelatin (gel strength $300 \mathrm{~g}$ Bloom, Type A, from porcine skin, Sigma-Aldrich, St. Louis, MO, USA) was dissolved in $100 \mathrm{~mL}$ of phosphate-buffered saline (PBS, Corning, Somerville, NY, USA) at $60^{\circ} \mathrm{C}$. A total of $2 \mathrm{~mL}$ of methacrylic anhydride (Manh, SigmaAldrich, St. Louis, MO, USA) was added dropwise and the $\mathrm{pH}$ was adjusted to 8 . The solution was kept at $60^{\circ} \mathrm{C}$ for $3 \mathrm{~h}$ with constant stirring. Then, the solution was diluted with $400 \mathrm{~mL}$ of PBS (pre-warmed to $40-50{ }^{\circ} \mathrm{C}$ ) and stirred for $15 \mathrm{~min}$. The solution was then transferred into 12-14 kDa MWCO dialysis membranes (VWR, Chicago, IL, USA) and dialyzed against DI water for one week, with twice daily water changes, before filtering and lyophilizing.

For MeHA synthesis, $0.2 \mathrm{~g}$ of HA (MW: 1.5-1.8 $\times 10^{6} \mathrm{Da}$, Sigma-Aldrich, St. Louis, $\mathrm{MO}$, USA) was dissolved in $60 \mathrm{~mL}$ DI water at room temperature with constant stirring overnight. The next day, $40 \mathrm{~mL}$ dimethylformamide (DMF, Sigma-Aldrich, St. Louis, MO, USA) was added dropwise using a glass pipette. Then, $0.8 \mathrm{~mL}$ of Manh was added dropwise and the $\mathrm{pH}$ was set to $8-9$ for the reaction to take place at $4{ }^{\circ} \mathrm{C}$ overnight. The next day, the mixture was placed in 12-14 kDa MWCO dialysis membranes and dialyzed 
against DI water for three days, by replacing the water 2-3 times a day. Finally, the MeHA solutions were filtered and lyophilized for further use.

\subsection{Cell Culture}

\subsection{1. hiPSC Culture and iCM Differentiation}

The DiPS 1016 SevA hiPSC line derived from human skin fibroblasts (Passage number 40-50) was seeded and kept in culture on Geltrex (1\% Invitrogen, Carlsbad, CA, USA)-coated culture flasks using mTeSR (StemCell Technologies, Vancouver, BC, Canada) supplemented with $1 \%$ penicillin (Pen) (VWR, Radnor, PA, USA) at $37{ }^{\circ} \mathrm{C}$ with $5 \% \mathrm{CO}_{2}$. When confluency of $80 \%$ was reached, the hiPSCs were detached using Accutase (StemCell Technologies, Vancouver, BC, Canada), and seeded in culture well plates in mTeSR1 media supplemented with Rho-associated, coiled-coil containing protein kinase (ROCK) inhibitor ( $5 \mu \mathrm{M}$, StemCell Technologies, Vancouver, BC, Canada). Until 95\% confluency was reached, the culture was maintained with daily media changes.

A previously established protocol was adapted to differentiate iCMs from hiPSCs [51]. Briefly, when the hiPSCs reached 95\% confluency, they were treated with RPMI Medium 1640 (Life Technologies, Carlsbad, CA, USA) supplemented with B27 without insulin ( $2 \%$, Invitrogen, Carlsbad, CA, USA), beta-mercaptoethanol (final concentration of $0.1 \mathrm{mM}$, Promega, Madison, WI, USA), and Pen (1\%) (CM (-)) with the addition of Wnt activator, CHIR99021 (CHIR) (12 $\mu \mathrm{M}$, Stemgent, Cambridge, MA, USA). Exactly twenty-four hours later, media was replaced with CM (-) without CHIR. On day 4, iCMs were treated with $\mathrm{CM}(-)$ media supplemented with the Wnt inhibitor IWP-4 (5 $\mu \mathrm{M}$, Stemgent, Cambridge, MA, USA). Media was changed back to CM (-) on day 6. Three days later (day 9), media was replaced with RPMI Medium 1640 supplemented with B27 (2\%, Invitrogen, Carlsbad, CA, USA), beta-mercaptoethanol (final concentration of $0.1 \mathrm{mM})$, and Pen $(1 \%)(\mathrm{CM}(+))$. After day 9 , media was changed every three days, and beating was observed generally by day 21 of differentiation as stated in previous papers [52-54].

\subsubsection{Human CF Culture}

Human cardiac fibroblasts (Passage number 4-6) (Cell Applications, San Diego, CA, USA) were kept in culture using DMEM High Glucose (Corning, Somerville, NY, USA) supplemented with fetal bovine serum (FBS, 10\%) (Hyclone, South Logan, UT, USA), penicillin-streptomycin (P/S, $1 \%$ ) (Gibco, Waltham, MA, USA), and SD208 ( $3 \mu \mathrm{M}$, TGF- $\beta$ pathway inhibitor) (Sigma-Aldrich, St. Louis, MO, USA) at $37{ }^{\circ} \mathrm{C}$ with $5 \% \mathrm{CO}_{2}$. The culture was maintained with daily half-media changes until they reached approximately $80 \%$ confluency.

\subsection{Preparation of Hydrogels for Material Characterization}

Four different hydrogel solutions were prepared: G, GE, GM, and GME. G solution was prepared by dissolving G $(10 \% w / v)$ and adding Irgacure 2959 PI $(0.05 \% w / v$, SigmaAldrich, St. Louis, MO, USA) in PBS. The solution was kept at $37^{\circ} \mathrm{C}$ until $\mathrm{G}$ was completely dissolved. To prepare the GE solution, $\mathrm{G}$ was prepared as explained above and mixed thoroughly with dhECM to achieve a final concentration of $10 \% w / v$ of $\mathrm{G}$ and $1 \mathrm{mg} / \mathrm{mL}$ of dhECM. MeHA was dissolved in PBS $(2 \% w / v)$, at $80^{\circ} \mathrm{C}$ for $1 \mathrm{~h}$. Then, it was mixed with G $(20 \% w / v)$ and PI $(0.2 \% w / v)$. To achieve a better mixture of GM hydrogels, the mixture was placed in an Eppendorf tube with a stir bar on a stirrer at $37{ }^{\circ} \mathrm{C}$ for an hour. Finally, the GME solution was prepared similarly, and dhECM was added after the GelMA and MeHA mixed completely and final concentrations of $1 \mathrm{mg} / \mathrm{mL}$, $10 \% w / v, 1 \% w / v$, and $0.1 \% w / v$ were achieved for dhECM, GelMA, MeHA, and PI, respectively. The microbial transglutaminase (mTGase, Modernist Pantry, Portsmouth, NH, USA) solution was prepared in PBS $(80 \mathrm{mg} / \mathrm{mL} w / v)$ and kept at $37^{\circ} \mathrm{C}$ until mTGase was completely dissolved.

After all the solutions were prepared, the hydrogels were prepared by transferring $100 \mu \mathrm{L}$ from each solution onto a stage, in-between $1 \mathrm{~mm}$ thick spacers, and a glass slide was 
placed on top of the solution to achieve the required thickness. The gels were then exposed to $6.9 \mathrm{~mW} / \mathrm{cm}^{2}$ UV irradiation by using a UV lamp (Lumen Dynamics, Mississauga, $\mathrm{ON}$, Canada). The gels were treated with $\mathrm{mTG}$ Tase solution for $30 \mathrm{~min}$ at $37^{\circ} \mathrm{C}$, then the mTGase solution was replaced with PBS. The gels were kept at $37^{\circ} \mathrm{C}$ overnight to achieve equilibrium swelling of the hydrogels.

\subsection{Materials Characterization}

\subsubsection{Mechanical Properties}

To measure the Young's modulus of each hydrogel, a compression test was conducted using a nanoindenter (Optics 11, Westwood, MA, USA) with an indentation probe (spring constant of $0.51 \mathrm{~N} / \mathrm{m}$, tip diameter of $46 \mu \mathrm{m}$ ) as described previously [64]. Young's modulus was calculated as the slope of the stress-strain curve in the elastic region, which was determined using an in-house MATLAB code.

\subsubsection{Swelling Test}

By measuring the volume change between the freshly prepared hydrogels and those that were incubated in PBS solution at $37^{\circ} \mathrm{C}$ for $24 \mathrm{~h}$, the swelling properties of the hydrogels were determined. To calculate the volume of the hydrogels, the surface area was multiplied by the thickness. To measure the surface area of the hydrogels, images of the gels were taken immediately after preparation and $24 \mathrm{~h}$ later and analyzed using ImageJ (National Institutes of Health, Bethesda, MD, USA). The gels were prepared to have an initial thickness of $1 \mathrm{~mm}$. The next day, the thickness of the gels was determined using the force reading in the rheometer, which showed zero up until the upper plate touched the surface of the gel and started increasing after contact occurred. The thickness reading at this contact point was used as the thickness of the gel.

\subsubsection{Enzymatic Degradation Test}

For the degradation test, the hydrogel solutions were prepared as described in the previous section. To prepare identical circular hydrogels, PDMS molds with a $6 \mathrm{~mm}$ diameter and $1 \mathrm{~mm}$ thickness were used. For one gel, $30 \mu \mathrm{L}$ of the solution was placed in the PDMS mold, and crosslinked with $30 \mathrm{~s} \mathrm{UV}$ exposure, followed by $30 \mathrm{~min}$ mTGase $(80 \mathrm{mg} / \mathrm{mL} \mathrm{w/v}$ in PBS) treatment. After polymerization, the hydrogel discs were transferred to 24-well plates and allowed to swell in PBS at $37^{\circ} \mathrm{C}$ overnight. The next day, the PBS was removed and $1 \mathrm{~mL}$ of collagenase type 2 ( $240 \mathrm{U} / \mathrm{mg}$, Worthington Biochemical, Lakewood, NJ, USA) with $1 \mathrm{U} / \mathrm{mL}$ concentration in PBS was added on top of G and GE hydrogels. Similarly, $0.5 \mathrm{~mL}$ of collagenase type $2(240 \mathrm{U} / \mathrm{mg}$, ) with $2 \mathrm{U} / \mathrm{mL}$ concentration in PBS and $0.5 \mathrm{~mL}$ of hyaluronidase type 2 from sheep testes ( $370 \mathrm{U} / \mathrm{mg}$, Sigma-Aldrich) with $200 \mathrm{U} / \mathrm{mL}$ concentration in PBS was added on top of the GM and GME hydrogels. The weight of the hydrogels was measured after carefully drying with a delicate tissue wipe (KimTech Science, Roswell, GA, Canada), every hour for the first $5 \mathrm{~h}$, then at 8, 18, and $24 \mathrm{~h}$ time points. For each time point, three samples were used, and the remaining weight (RW) percentage was calculated using Equation (2).

$$
\mathrm{RW}(\%)=100+\frac{(\text { weight at required time point }- \text { initial weight })}{\text { initial weight }} \times 100
$$

\subsubsection{Scanning Electron Microscopy}

The porosity of the G, GE, GM, and GME hydrogels was analyzed using field emission scanning electron microscopy (FESEM) (Model Magellan 400, FEI, Hillsboro, OR, USA) at the University of Notre Dame Integrated Imaging Facility. The hydrogels were prepared as described previously and placed at $-80^{\circ} \mathrm{C}$ overnight. The frozen samples were cut using a razor and lyophilized completely. The freeze-dried samples were then mounted on standard aluminum SEM specimen stubs using double-sided carbon tape. Finally, they were coated with iridium and imaged at $5.0 \mathrm{kV}$. 


\subsubsection{Rheological Properties}

Viscoelastic properties of the hydrogels were characterized using an HR-2 Hybrid Rheometer (TA Instruments, New Castle, DE, USA) with $8 \mathrm{~mm}$ diameter parallel-plate geometry. First, the storage $\left(G^{\prime}\right)$ and loss modulus $\left(G^{\prime \prime}\right)$ of the hydrogels were recorded for $1 \mathrm{~min}$ at $37^{\circ} \mathrm{C}$, under a fixed frequency of $1 \mathrm{~Hz}$ and strain of $3 \%$. Then, the storage and loss modulus of the hydrogels were recorded at $2 \%$ strain over a frequency range from 0.1 to $10 \mathrm{~Hz}$ at $37^{\circ} \mathrm{C}$ to observe the viscoelastic properties of the hydrogels. Finally, the shear stress and viscosity of each hydrogel were recorded for a shear rate change from 0 to $901 / \mathrm{s}$.

\subsubsection{Printability}

The hydrogels were prepared as previously described. After preparation, each hydrogel was transferred into a cartridge and placed in an ice bath for 1-2 min to achieve the required consistency for printing. A CELLINK Inkredible+ Bioprinter (CELLINK, Gothenburg, Sweden) was used for printing. A grid pattern consisting of two layers with dimensions of $0.6 \mathrm{~cm} \times 0.6 \mathrm{~cm}$ was printed on a charged glass placed in a $35 \mathrm{~cm}$ dish (Figure S2) using a $22 \mathrm{G}$ nozzle with a translational speed of $75 \mathrm{~mm} / \mathrm{min}$. Right after printing, the constructs were treated with $30 \mathrm{~s} \mathrm{UV}\left(6.9 \mathrm{~W} / \mathrm{cm}^{2} \mathrm{UV}\right.$ radiation) using a UV lamp (Lumen Dynamics, Mississauga, ON, Canada). Printed constructs were treated with mTGase solution for $30 \mathrm{~min}$ and kept at $37^{\circ} \mathrm{C}$ overnight. The next day, brightfield images were taken and printability was quantified by measuring the distance between neighboring lines on the second day for every small grid.

\subsection{Printing the Tissue Constructs}

\subsubsection{Viability Assessment}

iCMs were reseeded on culture days 30-50. On day 3, the cells were collected using Trypsin ethylenediamine tetraacetic acid (EDTA) (VWR, Chicago, IL, USA). Cells were mixed with either GelMA ( $10 \% w / v$ final) or GelMA (10\% $w / v$ final), $-\operatorname{dhECM~}(1 \mathrm{mg} / \mathrm{mL}$ final) hydrogels with $0.05 \%$ PI to have a final density of $20 \mathrm{mil} / \mathrm{mL}$.

hCFs were kept in culture until they reached $90 \%$ confluency in the T75 flask. They were then collected using Trypsin EDTA. Cells were mixed with either GelMA ( $10 \% w / v$ final-MeHA ( $1 \% w / v$ final) or GelMA (10\% $w / v$ final)-MeHA ( $1 \% w / v$ final), -dhECM $(1 \mathrm{mg} / \mathrm{mL}$ final) hydrogels with $0.1 \%$ PI to have a final density of $1 \mathrm{mil} / \mathrm{mL}$.

The samples were prepared as described in the previous section and placed in a cartridge (500 $\mu \mathrm{L}$ total volume). The same printing protocol was followed, and the printed constructs were washed with PBS. The constructs with iCMs were then washed with $\mathrm{CM}+$, and the constructs with hCFs were washed using DMEM Complete media for $5 \mathrm{~min}$ prior to $\mathrm{mTGase}(80 \mathrm{mg} / \mathrm{mL} w / v$ prepared in cell-specific culture media) treatment for $30 \mathrm{~min}$. After $30 \mathrm{~min}$, mTGase was removed and the constructs were kept in cell-specific media for $15 \mathrm{~min}$ before changing to fresh media and kept in culture.

The next day after printing, the live/dead assay was performed (Life Technologies, Carlsbad, CA, USA) following the manufacturer's instructions. Briefly, the constructs were washed with PBS and incubated at $37^{\circ} \mathrm{C}$ for $30 \mathrm{~min}$ in a solution containing Calcein AM (live cells, green, $2 \mu \mathrm{M}$ ), Ethidium homodimer- 1 (dead cells, red, $4 \mu \mathrm{M}$ ), and Hoescht (Thermo Scientific, Waltham, MA, USA). For each construct, z-serial images were then taken with a fluorescence microscope (Zeiss, Hamamatsu ORCA flash 4.0, Thornwood, NY, USA). Live and dead cells were counted in ImageJ software. Live cell percentage was calculated by using Equation (3).

$$
\text { Live cell }(\%)=[(\text { live cell number }) /(\text { total cell number })]^{* 100}
$$

\subsubsection{Beating and Phenotypical Characterization}

To analyze the contractility of iCMs, a block-matching algorithm was performed using MATLAB as described previously [50]. By using this method on the brightfield 
videos, the beating velocity and frequency of the iCMs were calculated and the heat maps were plotted.

For immunostaining, the 3D printed constructs were kept in culture for three weeks before fixing using paraformaldehyde (4\%, Electron Microscopy Sciences, Hatfield, PA, USA) for 45 min at RT. After fixing, they were washed with PBS and then permeabilized in Triton X-100 (0.1\%, Sigma-Aldrich, St. Louis, MO, USA) for $45 \mathrm{~min}$. They were washed with PBS and blocked using goat serum (10\%, Sigma-Aldrich, St. Louis, MO, USA) for $2 \mathrm{~h}$. After blocking, constructs were incubated with sarcomeric alpha-actinin (ab9465, Abcam, Cambridge, UK), and connexin 43 (CX43) (ab11370, Abcam, Cambridge, UK) primary antibodies diluted 1:200 and 1:100, respectively, in goat serum at $4{ }^{\circ} \mathrm{C}$ overnight. The next day, the constructs were washed thoroughly with PBS and then incubated with Alexa Fluor 647 (A21245, Life Technologies, Carlsbad, CA, USA) and Alexa Fluor 488 (A11001, Life Technologies, Carlsbad, CA, USA) diluted 1:200 in goat serum at $4{ }^{\circ} \mathrm{C}$ for $6 \mathrm{~h}$. After incubation, constructs were washed with PBS until no background was seen. The samples were then fixed using ProLong Gold mounting medium (Thermo Scientific, Waltham, MA, USA) with DAPI (ab104139, Abcam, Cambridge, UK). Imaging was then performed using a fluorescence microscope (Zeiss, Hamamatsu ORCA flash 4.0, Thornwood, NY, USA).

\subsubsection{Printing the Infarct Boundary Zone}

Bioinks were prepared by mixing iCMs in GE and hCFs in the GME hydrogels as described above. Prior to mixing, the cells were tagged using Cell Tracker green (C2925) and deep red (C34656), (Life Technologies, Carlsbad, CA, USA) by following the manufacturer's instructions. Using a custom-made G-Code, the infarct region was printed using two printheads. The next day, images were taken with a fluorescence microscope (Zeiss, Hamamatsu ORCA flash 4.0, Thornwood, NY, USA). For immunostaining, the printing was performed without mixing the cells with Cell Tracker. The next day, immunostaining was performed on the printed infarct region constructs following the protocol given above (for Vimentin (ab137321, Abcam, United Kingdom, was diluted 1:200). Imaging was performed using a fluorescence microscope (Zeiss, Hamamatsu ORCA flash 4.0, Thornwood, NY, USA).

\subsection{Statistical Analysis}

For all replicates, the mean \pm standard deviation (SD) was reported. To find any statistically significant differences, one-way analysis of variance (ANOVA) followed by Tukey's post-hoc was used. To compare two individual groups, the student's t-test was used. All $p$-values reported were two-sided and $p<0.05$ was considered statistically significant. Sample size $(n) \geq 3$ for all individual experiments.

Supplementary Materials: The following are available online at https:/ /www.mdpi.com/article/10 .3390/gels7020070/s1, Figure S1: H-NMR analysis of (A) gelatin and GelMA, (B) hyaluronic acid and MeHA, Figure S2: Parafilm coating (A) on the printing stage, (B) in the dish under the glass, Figure S3: Young's modulus of hydrogels with visible light crosslinking, Figure S4: Printed boundary region using iCMs in the GelMA-dhECM bioink (green), and hCFs encapsulated in the GelMAMeHA-dhECM bioink (magenta), Video S1: Tissue-like beating of iCMs encapsulated in GelMA. Video S2: Tissue-like beating of iCMs encapsulated in GelMA-dhECM. Video S3: Brightfield video of the beating of iCMs encapsulated in GelMA taken nine days after printing. Video S4: Brightfield video of the beating of iCMs encapsulated in GelMA-dhECM taken nine days after printing.

Author Contributions: Conceptualization, G.B. and P.Z.; Methodology, G.B., S.G.O., and P.Z.; Software, G.B.; Validation, G.B., S.G.O., B.W.E., and P.Z.; Formal analysis, G.B.; Investigation, G.B.; Resources, P.Z.; Data curation, G.B. and S.G.O.; Writing-original draft preparation, G.B.; Writingreview and editing, G.B., S.G.O., B.W.E., and P.Z.; Visualization, G.B.; Supervision, P.Z.; Project administration, P.Z.; Funding acquisition, P.Z. All authors have read and agreed to the published version of the manuscript. 
Funding: This research was funded by NIH Award \#1 R01 HL141909-01A1, NSF Award \#1651385, and the Naughton Fellowship.

Institutional Review Board Statement: The study was conducted according to the guidelines of the Declaration of Helsinki. Institutional Review Board approval was waived for this study because the Research Compliance team at University of Notre Dame does not consider our research as human subject research since the Indiana Donor Network does not provide any identifying information about the samples to the researchers.

Informed Consent Statement: Patient consent was waived due to patients being organ donors.

Data Availability Statement: The raw/processed data required to reproduce these findings can be shared upon reasonable request.

Acknowledgments: We would like to thank NDIIF (special thanks to Tatyana Orlova) for their help with SEM imaging, and Evgenii Kovrigin and Magnetic Resonance Research Center of the University of Notre Dame for their help with H NMR measurements. Figures 1A and 7A were created with BioRender.com (accessed on 7 June 2021).

Conflicts of Interest: The authors declare no conflict of interest.

\section{References}

1. Heron, M. Deaths: Leading Causes for 2017. Natl. Vital Stat. Rep. 2019, 68, 77.

2. Thomas, H.; Diamond, J.; Vieco, A.; Chaudhuri, S.; Shinnar, E.; Cromer, S.; Perel, P.; Mensah, G.A.; Narula, J.; Johnson, C.O.; et al. Global Atlas of Cardiovascular Disease 2000-2016: The Path to Prevention and Control. Glob. Heart 2018, 13, 143. [CrossRef]

3. Richards, D.J.; Li, Y.; Kerr, C.M.; Yao, J.; Beeson, G.C.; Coyle, R.C.; Chen, X.; Jia, J.; Damon, B.; Wilson, R.; et al. Human Cardiac Organoids for the Modelling of Myocardial Infarction and Drug Cardiotoxicity. Nat. Biomed. Eng. 2020, 4, 446-462. [CrossRef] [PubMed]

4. Shin, Y.J.; Shafranek, R.T.; Tsui, J.H.; Walcott, J.; Nelson, A.; Kim, D.-H. 3D Bioprinting of Mechanically Tuned Bioinks Derived from Cardiac Decellularized Extracellular Matrix. Acta Biomater. 2021, 119, 75-88. [CrossRef] [PubMed]

5. Borovjagin, A.V.; Ogle, B.M.; Berry, J.L.; Zhang, J. From Microscale Devices to 3D Printing: Advances in Fabrication of 3D Cardiovascular Tissues. Circ. Res. 2017, 120, 150-165. [CrossRef]

6. Bejleri, D.; Streeter, B.W.; Nachlas, A.L.Y.; Brown, M.E.; Gaetani, R.; Christman, K.L.; Davis, M.E. A Bioprinted Cardiac Patch Composed of Cardiac-Specific Extracellular Matrix and Progenitor Cells for Heart Repair. Adv. Healthc. Mater. 2018, 7, 1800672. [CrossRef]

7. Ong, C.S.; Fukunishi, T.; Zhang, H.; Huang, C.Y.; Nashed, A.; Blazeski, A.; DiSilvestre, D.; Vricella, L.; Conte, J.; Tung, L.; et al. Biomaterial-Free Three-Dimensional Bioprinting of Cardiac Tissue Using Human Induced Pluripotent Stem Cell Derived Cardiomyocytes. Sci. Rep. 2017, 7, 4566. [CrossRef]

8. Liu, J.; He, J.; Liu, J.; Ma, X.; Chen, Q.; Lawrence, N.; Zhu, W.; Xu, Y.; Chen, S. Rapid 3D Bioprinting of in Vitro Cardiac Tissue Models Using Human Embryonic Stem Cell-Derived Cardiomyocytes. Bioprinting 2019, e00040. [CrossRef]

9. Liu, W.; Heinrich, M.A.; Zhou, Y.; Akpek, A.; Hu, N.; Liu, X.; Guan, X.; Zhong, Z.; Jin, X.; Khademhosseini, A.; et al. Extrusion Bioprinting of Shear-Thinning Gelatin Methacryloyl Bioinks. Adv. Healthc. Mater. 2017, 6, 1601451. [CrossRef]

10. Liu, W.; Zhong, Z.; Hu, N.; Zhou, Y.; Maggio, L.; Miri, A.K.; Fragasso, A.; Jin, X.; Khademhosseini, A.; Zhang, Y.S. Coaxial Extrusion Bioprinting of 3D Microfibrous Constructs with Cell-Favorable Gelatin Methacryloyl Microenvironments. Biofabrication 2018, 10, 024102. [CrossRef]

11. Cui, H.; Miao, S.; Esworthy, T.; Zhou, X.; Lee, S.; Liu, C.; Yu, Z.; Fisher, J.P.; Mohiuddin, M.; Zhang, L.G. 3D Bioprinting for Cardiovascular Regeneration and Pharmacology. Adv. Drug Deliv. Rev. 2018, 132, 252-269. [CrossRef]

12. Koti, P.; Muselimyan, N.; Mirdamadi, E.; Asfour, H.; Sarvazyan, N.A. Use of GelMA for 3D Printing of Cardiac Myocytes and Fibroblasts. J. 3D Print. Med. 2019. [CrossRef] [PubMed]

13. Skardal, A.; Devarasetty, M.; Kang, H.-W.; Mead, I.; Bishop, C.; Shupe, T.; Lee, S.J.; Jackson, J.; Yoo, J.; Soker, S.; et al. A Hydrogel Bioink Toolkit for Mimicking Native Tissue Biochemical and Mechanical Properties in Bioprinted Tissue Constructs. Acta Biomater. 2015, 25, 24-34. [CrossRef] [PubMed]

14. Lee, A.; Hudson, A.R.; Shiwarski, D.J.; Tashman, J.W.; Hinton, T.J.; Yerneni, S.; Bliley, J.M.; Campbell, P.G.; Feinberg, A.W. 3D Bioprinting of Collagen to Rebuild Components of the Human Heart. Science 2019, 365, 482-487. [CrossRef]

15. Yin, J.; Yan, M.; Wang, Y.; Fu, J.; Suo, H. 3D Bioprinting of Low-Concentration Cell-Laden Gelatin Methacrylate (GelMA) Bioinks with a Two-Step Cross-Linking Strategy. ACS Appl. Mater. Interfaces 2018, 10, 6849-6857. [CrossRef] [PubMed]

16. Anil Kumar, S.; Alonzo, M.; Allen, S.C.; Abelseth, L.; Thakur, V.; Akimoto, J.; Ito, Y.; Willerth, S.M.; Suggs, L.; Chattopadhyay, M.; et al. A Visible Light-Cross-Linkable, Fibrin-Gelatin-Based Bioprinted Construct with Human Cardiomyocytes and Fibroblasts. ACS Biomater. Sci. Eng. 2019, 5, 4551-4563. [CrossRef] [PubMed]

17. Axpe, E.; Oyen, M. Applications of Alginate-Based Bioinks in 3D Bioprinting. Int. J. Mol. Sci. 2016, 17, 1976. [CrossRef] 
18. Giuseppe, M.D.; Law, N.; Webb, B.; Macrae, R.A.; Liew, L.J.; Sercombe, T.B.; Dilley, R.J.; Doyle, B.J. Mechanical Behaviour of Alginate-Gelatin Hydrogels for 3D Bioprinting. J. Mech. Behav. Biomed. Mater. 2018, 79, 150-157. [CrossRef] [PubMed]

19. Skardal, A.; Zhang, J.; McCoard, L.; Xu, X.; Oottamasathien, S.; Prestwich, G.D. Photocrosslinkable Hyaluronan-Gelatin Hydrogels for Two-Step Bioprinting. Tissue Eng. Part A 2010, 16, 2675-2685. [CrossRef] [PubMed]

20. Costantini, M.; Idaszek, J.; Szöke, K.; Jaroszewicz, J.; Dentini, M.; Barbetta, A.; Brinchmann, J.E.; Święszkowski, W. 3D Bioprinting of BM-MSCs-Loaded ECM Biomimetic Hydrogels for in Vitro Neocartilage Formation. Biofabrication 2016, 8, 035002. [CrossRef]

21. Bejleri, D.; Davis, M.E. Decellularized Extracellular Matrix Materials for Cardiac Repair and Regeneration. Adv. Healthc. Mater. 2019, 1801217. [CrossRef] [PubMed]

22. Pati, F.; Jang, J.; Ha, D.-H.; Won Kim, S.; Rhie, J.-W.; Shim, J.-H.; Kim, D.-H.; Cho, D.-W. Printing Three-Dimensional Tissue Analogues with Decellularized Extracellular Matrix Bioink. Nat. Commun. 2014, 5, 3935. [CrossRef] [PubMed]

23. Ahn, G.; Min, K.-H.; Kim, C.; Lee, J.-S.; Kang, D.; Won, J.-Y.; Cho, D.-W.; Kim, J.-Y.; Jin, S.; Yun, W.-S.; et al. Precise Stacking of Decellularized Extracellular Matrix Based 3D Cell-Laden Constructs by a 3D Cell Printing System Equipped with Heating Modules. Sci. Rep. 2017, 7, 8624. [CrossRef] [PubMed]

24. Jang, J.; Park, H.-J.; Kim, S.-W.; Kim, H.; Park, J.Y.; Na, S.J.; Kim, H.J.; Park, M.N.; Choi, S.H.; Park, S.H.; et al. 3D Printed Complex Tissue Construct Using Stem Cell-Laden Decellularized Extracellular Matrix Bioinks for Cardiac Repair. Biomaterials 2017, 112, 264-274. [CrossRef] [PubMed]

25. Yu, C.; Ma, X.; Zhu, W.; Wang, P.; Miller, K.L.; Stupin, J.; Koroleva-Maharajh, A.; Hairabedian, A.; Chen, S. Scanningless and Continuous 3D Bioprinting of Human Tissues with Decellularized Extracellular Matrix. Biomaterials 2019, 194, 1-13. [CrossRef]

26. Ozcebe, S.G.; Bahcecioglu, G.; Yue, X.S.; Zorlutuna, P. Effect of Cellular and ECM Aging on Human IPSC-Derived Cardiomyocyte Performance, Maturity and Senescence. Biomaterials 2021, 268, 120554. [CrossRef] [PubMed]

27. Stoppel, W.L.; Hu, D.; Domian, I.J.; Kaplan, D.L.; Black, L.D. Anisotropic Silk Biomaterials Containing Cardiac Extracellular Matrix for Cardiac Tissue Engineering. Biomed. Mater. 2015, 10, 034105. [CrossRef]

28. Stoppel, W.L.; Gao, A.E.; Greaney, A.M.; Partlow, B.P.; Bretherton, R.C.; Kaplan, D.L.; Black, L.D. Elastic, Silk-Cardiac Extracellular Matrix Hydrogels Exhibit Time-Dependent Stiffening That Modulates Cardiac Fibroblast Response: Silk-extracellular matrix hydrogels modulate cardiac fibroblast response. J. Biomed. Mater. Res. Part A 2016, 104, 3058-3072. [CrossRef]

29. Efraim, Y.; Sarig, H.; Cohen Anavy, N.; Sarig, U.; de Berardinis, E.; Chaw, S.-Y.; Krishnamoorthi, M.; Kalifa, J.; Bogireddi, H.; Duc, T.V.; et al. Biohybrid Cardiac ECM-Based Hydrogels Improve Long Term Cardiac Function Post Myocardial Infarction. Acta Biomater. 2017, 50, 220-233. [CrossRef]

30. Williams, C.; Budina, E.; Stoppel, W.L.; Sullivan, K.E.; Emani, S.; Emani, S.M.; Black, L.D. Cardiac Extracellular Matrix-Fibrin Hybrid Scaffolds with Tunable Properties for Cardiovascular Tissue Engineering. Acta Biomater. 2015, 14, 84-95. [CrossRef]

31. Grover, G.N.; Rao, N.; Christman, K.L. Myocardial Matrix-Polyethylene Glycol Hybrid Hydrogels for Tissue Engineering. Nanotechnology 2014, 25, 014011. [CrossRef]

32. Billiet, T.; Gevaert, E.; De Schryver, T.; Cornelissen, M.; Dubruel, P. The 3D Printing of Gelatin Methacrylamide Cell-Laden Tissue-Engineered Constructs with High Cell Viability. Biomaterials 2014, 35, 49-62. [CrossRef] [PubMed]

33. Zhou, M.; Lee, B.H.; Tan, Y.J.; Tan, L.P. Microbial Transglutaminase Induced Controlled Crosslinking of Gelatin Methacryloyl to Tailor Rheological Properties for 3D Printing. Biofabrication 2019, 11, 025011. [CrossRef]

34. Wang, H.; Zhou, L.; Liao, J.; Tan, Y.; Ouyang, K.; Ning, C.; Ni, G.; Tan, G. Cell-Laden Photocrosslinked GelMA-DexMA Copolymer Hydrogels with Tunable Mechanical Properties for Tissue Engineering. J. Mater. Sci. Mater. Med. 2014, 25, 2173-2183. [CrossRef]

35. Das, S.; Pati, F.; Choi, Y.-J.; Rijal, G.; Shim, J.-H.; Kim, S.W.; Ray, A.R.; Cho, D.-W.; Ghosh, S. Bioprintable, Cell-Laden Silk Fibroin-Gelatin Hydrogel Supporting Multilineage Differentiation of Stem Cells for Fabrication of Three-Dimensional Tissue Constructs. Acta Biomater. 2015, 11, 233-246. [CrossRef] [PubMed]

36. Camci-Unal, G.; Cuttica, D.; Annabi, N.; Demarchi, D.; Khademhosseini, A. Synthesis and Characterization of Hybrid Hyaluronic Acid-Gelatin Hydrogels. Biomacromolecules 2013, 14, 1085-1092. [CrossRef] [PubMed]

37. Shin, H.; Olsen, B.D.; Khademhosseini, A. The Mechanical Properties and Cytotoxicity of Cell-Laden Double-Network Hydrogels Based on Photocrosslinkable Gelatin and Gellan Gum Biomacromolecules. Biomaterials 2012, 33, 3143-3152. [CrossRef] [PubMed]

38. Rastin, H.; Ormsby, R.T.; Atkins, G.J.; Losic, D. 3D Bioprinting of Methylcellulose/Gelatin-Methacryloyl (MC/GelMA) Bioink with High Shape Integrity. ACS Appl. Bio Mater. 2020, 3, 1815-1826. [CrossRef]

39. Melchels, F.P.W.; Dhert, W.J.A.; Hutmacher, D.W.; Malda, J. Development and Characterisation of a New Bioink for Additive Tissue Manufacturing. J. Mater. Chem. B 2014, 2, 2282. [CrossRef]

40. Schuurman, W.; Levett, P.A.; Pot, M.W.; van Weeren, P.R.; Dhert, W.J.A.; Hutmacher, D.W.; Melchels, F.P.W.; Klein, T.J.; Malda, J. Gelatin-methacrylamide hydrogels as potential biomaterials for fabrication of tissue-engineered cartilage constructs. Macromol. Biosci. 2013, 13, 551-561. [CrossRef]

41. Lim, K.S.; Schon, B.S.; Mekhileri, N.V.; Brown, G.C.J.; Chia, C.M.; Prabakar, S.; Hooper, G.J.; Woodfield, T.B.F. New Visible-Light Photoinitiating System for Improved Print Fidelity in Gelatin-Based Bioinks. ACS Biomater. Sci. Eng. 2016, 2, 1752-1762. [CrossRef]

42. Xavier, J.R.; Thakur, T.; Desai, P.; Jaiswal, M.K.; Sears, N.; Cosgriff-Hernandez, E.; Kaunas, R.; Gaharwar, A.K. Bioactive Nanoengineered Hydrogels for Bone Tissue Engineering: A Growth-Factor-Free Approach. ACS Nano 2015, 9 , 3109-3118. [CrossRef] [PubMed] 
43. Poldervaart, M.T.; Goversen, B.; de Ruijter, M.; Abbadessa, A.; Melchels, F.P.W.; Öner, F.C.; Dhert, W.J.A.; Vermonden, T.; Alblas, J. 3D Bioprinting of Methacrylated Hyaluronic Acid (MeHA) Hydrogel with Intrinsic Osteogenicity. PLoS ONE 2017, 12, e0177628. [CrossRef] [PubMed]

44. Frantz, C.; Stewart, K.M.; Weaver, V.M. The Extracellular Matrix at a Glance. J. Cell Sci. 2010, 123, 4195-4200. [CrossRef] [PubMed]

45. Rao Pattabhi, S.; Martinez, J.S.; Keller, T.C.S. Decellularized ECM Effects on Human Mesenchymal Stem Cell Stemness and Differentiation. Differentiation 2014, 88, 131-143. [CrossRef]

46. Crapo, P.M.; Gilbert, T.W.; Badylak, S.F. An Overview of Tissue and Whole Organ Decellularization Processes. Biomaterials 2011, 32, 3233-3243. [CrossRef]

47. Johnson, T.D.; DeQuach, J.A.; Gaetani, R.; Ungerleider, J.; Elhag, D.; Nigam, V.; Behfar, A.; Christman, K.L. Human versus Porcine Tissue Sourcing for an Injectable Myocardial Matrix Hydrogel. Biomater. Sci. 2014, 2, 735-744. [CrossRef]

48. Vandaele, J.; Louis, B.; Liu, K.; Camacho, R.J.; Kouwer, P.H.; Rocha, S. Structural Characterization of Fibrous Synthetic Hydrogels Using Fluorescence Microscopy. Soft Matter. 2020, 16, 4210-4219. [CrossRef]

49. Basara, G.; Yue, X.; Zorlutuna, P. Dual Crosslinked Gelatin Methacryloyl Hydrogels for Photolithography and 3D Printing. Gels 2019, 5, 34. [CrossRef]

50. Acun, A.; Nguyen, T.D.; Zorlutuna, P. In Vitro Aged, HiPSC-Origin Engineered Heart Tissue Models with Age-Dependent Functional Deterioration to Study Myocardial Infarction. Acta Biomater. 2019, 94, 372-391. [CrossRef] [PubMed]

51. Rad, E.R.; Vahabi, H.; Formela, K.; Saeb, M.R.; Thomas, S. Injectable Poloxamer/Graphene Oxide Hydrogels with Well-controlled Mechanical and Rheological Properties. Polym. Adv. Technol. 2019, 30, 2250-2260. [CrossRef]

52. Pukánszky, B.; Tüdõs, F. Miscibility and Mechanical Properties of Polymer Blends. Makromol. Chem. Macromol. Symp. 1990, 38, 221-231. [CrossRef]

53. Münstedt, H. Rheological Behavior of Compatibilized Blends. In Rheological and Morphological Properties of Dispersed Polymeric Materials; Carl Hanser Verlag GmbH \& Co. KG: Munich, Germany, 2016; pp. 349-361, ISBN 978-1-56990-607-1.

54. Lee, B.; Lum, N.; Seow, L.; Lim, P.; Tan, L. Synthesis and Characterization of Types A and B Gelatin Methacryloyl for Bioink Applications. Materials 2016, 9, 797. [CrossRef]

55. Zhao, Y.; Li, Y.; Mao, S.; Sun, W.; Yao, R. The Influence of Printing Parameters on Cell Survival Rate and Printability in Microextrusion-Based 3D Cell Printing Technology. Biofabrication 2015, 7, 045002. [CrossRef] [PubMed]

56. Acun, A.; Vural, D.C.; Zorlutuna, P. A Tissue Engineered Model of Aging: Interdependence and Cooperative Effects in Failing Tissues. Sci. Rep. 2017, 7, 5051. [CrossRef]

57. Huebsch, N.; Loskill, P.; Mandegar, M.A.; Marks, N.C.; Sheehan, A.S.; Ma, Z.; Mathur, A.; Nguyen, T.N.; Yoo, J.C.; Judge, L.M.; et al. Automated Video-Based Analysis of Contractility and Calcium Flux in Human-Induced Pluripotent Stem Cell-Derived Cardiomyocytes Cultured over Different Spatial Scales. Tissue Eng. Part C Methods 2014, 21, 467-479. [CrossRef]

58. Basara, G.; Saeidi-Javash, M.; Ren, X.; Bahcecioglu, G.; Wyatt, B.C.; Anasori, B.; Zhang, Y.; Zorlutuna, P. Electrically Conductive 3D Printed Ti3C2Tx MXene-PEG Composite Constructs for Cardiac Tissue Engineering. Acta Biomater. 2020. [CrossRef]

59. Ribeiro, A.J.S.; Ang, Y.-S.; Fu, J.-D.; Rivas, R.N.; Mohamed, T.M.A.; Higgs, G.C.; Srivastava, D.; Pruitt, B.L. Contractility of Single Cardiomyocytes Differentiated from Pluripotent Stem Cells Depends on Physiological Shape and Substrate Stiffness. Proc. Natl. Acad. Sci. USA 2015, 112, 12705-12710. [CrossRef]

60. Kung, G.L.; Vaseghi, M.; Gahm, J.K.; Shevtsov, J.; Garfinkel, A.; Shivkumar, K.; Ennis, D.B. Microstructural Infarct Border Zone Remodeling in the Post-Infarct Swine Heart Measured by Diffusion Tensor MRI. Front. Physiol. 2018, 9. [CrossRef] [PubMed]

61. Nguyen, D.T.; Nagarajan, N.; Zorlutuna, P. Effect of Substrate Stiffness on Mechanical Coupling and Force Propagation at the Infarct Boundary. Biophys. J. 2018, 115, 1966-1980. [CrossRef] [PubMed]

62. Mendonca Costa, C.; Plank, G.; Rinaldi, C.A.; Niederer, S.A.; Bishop, M.J. Modeling the Electrophysiological Properties of the Infarct Border Zone. Front. Physiol. 2018, 9. [CrossRef] [PubMed]

63. Nichol, J.W.; Koshy, S.T.; Bae, H.; Hwang, C.M.; Yamanlar, S.; Khademhosseini, A. Cell-Laden Microengineered Gelatin Methacrylate Hydrogels. Biomaterials 2010, 31, 5536-5544. [CrossRef] [PubMed]

64. Casey, J.; Yue, X.; Nguyen, T.D.; Acun, A.; Zellmer, V.R.; Zhang, S.; Zorlutuna, P. 3D Hydrogel-Based Microwell Arrays as a Tumor Microenvironment Model to Study Breast Cancer Growth. Biomed. Mater. 2017, 12, 025009. [CrossRef] [PubMed] 